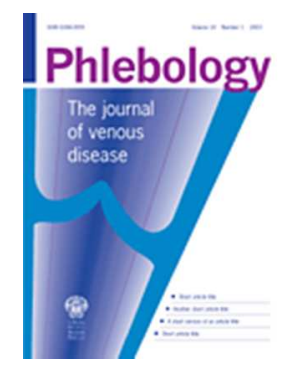

\title{
Effect of Aminaphtone on in vitro vascular permeability and capillary-like maintenance
}

\begin{tabular}{|r|l|}
\hline Journal: & Phlebology \\
\hline Manuscript ID & PHLEB-17-090.R1 \\
\hline Manuscript Type: & Original Article \\
\hline Date Submitted by the Author: & 27-Aug-2017 \\
\hline Complete List of Authors: & $\begin{array}{l}\text { Felice, Francesca; Laboratorio di ricerca cardiovascolare, dip Cardiotoracico } \\
\text { e vascolare - Università di Pisa } \\
\text { Belardinelli, Ester; University of Pisa, Cardiovascular Research Laboratory, } \\
\text { Department of Surgical Medical and Molecular Pathology and Critic Area } \\
\text { Frullini, Alessandro; studio medico flebologico, } \\
\text { Santoni, Tatiana; University of Pisa, Department of Surgical Medical and } \\
\text { Molecular Pathology and Critic Area } \\
\text { Imbalzano, Egidio; Universita degli Studi di Messina, Department of Clinical } \\
\text { and Experimental Medicine } \\
\text { Di Stefano, Rossella; U.O. angiologia universitaria, Dip Cardiotoracico e } \\
\text { Vascolare - Università di Pisa }\end{array}$ \\
\hline Revised Keywords: & \begin{tabular}{l} 
Chronic venous insufficiency, Pharmacologic agents \\
\hline
\end{tabular} \\
\hline
\end{tabular}




\section{Effect of Aminaphtone on in vitro vascular permeability and capillary-like maintenance}

Francesca Felice ${ }^{\text {a, }}$, Ester Belardinelli ${ }^{a}$, Alessandro Frullini ${ }^{\mathrm{b}}$, Tatiana Santoni ${ }^{\mathrm{a}}$, Egidio Imbalzano $^{\mathrm{c}}$, Rossella Di Stefano ${ }^{\mathrm{a}}$

${ }^{\text {a }}$ Cardiovascular Research Laboratory, Department of Surgical Medical and Molecular Pathology and Critic Area, University of Pisa, Via Paradisa, 2 - 56100 Pisa, Italy

${ }^{\mathrm{b}}$ Studio medico flebologico, Figline Valdarno, Florence, Italy

${ }^{\mathrm{c}}$ Department of Clinical and Experimental Medicine, University of Messina, Via Consolare Valeria, Gazzi, 98125 Messina, Italy.

\section{*Corresponding author:}

Francesca Felice, Cardiovascular Research Laboratory, Department of Surgical Medical and Molecular Pathology and Critic Area, University of Pisa, Via Paradisa, 2 - 56100

Pisa, Italy

Email: francesca.felice77@,hotmail.it

Phone: +39050995836 


\begin{abstract}
Aminaphtone (AMNA), a naphtohydrochinone used in the treatment of capillary disorders, may affect oedema in chronic venous insufficiency (CVI). Aim of study is to investigate the effect of AMNA on vascular endothelial permeability in vitro and its effects on three-dimensional capillary-like structures formed by Human Umbilical Vein Endothelial Cells (HUVECs).

HUVECs were treated with $50 \mathrm{ng} / \mathrm{ml}$ VEGF for $2 \mathrm{~h}$ and AMNA for $6 \mathrm{~h}$. Permeability assay, VE-cadherin expression and Matrigel assay were performed.

VEGF-induced permeability was significantly decreased by AMNA in a range concentration of 1-20 $\mu \mathrm{g} / \mathrm{ml}$. AMNA restored VE-cadherin expression. Finally, 6h pretreatment with AMNA significantly preserved capillary-like structures formed by HUVECs on Matrigel up to $48 \mathrm{~h}$ compared to untreated cells.

AMNA significantly protects endothelium permeability and stabilises endothelial cells organised in capillary-like structures, modulating VE-cadherin expression. These data might explain the clinical benefict of AMNA on CVI.
\end{abstract}

Keywords. Aminaphtone, Human Umbilical Vein Endothelial Cells, permeability, chronic venous insufficiency, capillary fragility, VE-cadherin 


\section{Introduction}

Vascular permeability is an extremely complicated process that is affected by many different variables ${ }^{1}$. A rapid increase in vascular permeability occurs when the microvasculature is exposed to any of a number of vascular permeabilising factors, e.g. vascular endothelial growth factor A (VEGF-A), histamine, platelet activating factor ${ }^{1}$. This process has been implicated in many pathological conditions such as angiogenesis, ischaemic heart disease, acute and chronic inflammation, trauma, wound-healing ${ }^{2}$. The dynamic equilibrium between cell adhesion and cytoskeleton contraction plays an important role in maintaining the normal function of endothelial permeability ${ }^{3}$. The intercellular junctions of endothelial cells have an important barrier function regulating the permeability to small molecules and even to cells ${ }^{4}$. Several families of cytoadhesive proteins, such as the selectins, members of the immunoglobulin (Ig) superfamily, and cadherins, play major roles in mediating cell-cell interactions and therefore are candidates for receptors involved in capillary tube formation ${ }^{5}$. Endothelial cells express both VE-(vascular endothelial) and $\mathrm{N}$-(neuronal) cadherins. Whereas VE-cadherin is localised at sites of cell-cell contact, N-cadherin is distributed diffusely over the cell surface and does not seem to contribute to cell-cell adhesion ${ }^{6}$.

VE-cadherin and N-cadherin have been shown to participate in capillary tube formation. In particular, antibodies directed against VE-cadherin, but not against $\mathrm{N}$-cadherin, PECAM-1 (Ig superfamily) or $\alpha_{\mathrm{v}} \beta_{3}$ integrin, markedly inhibited the generation of capillary tubes ${ }^{7,8}$. Moreover, it has been demonstrated that blocking VE-cadherin 
function leads to a marked reorganisation of the actin cytoskeleton, increased monolayer permeability and enhanced neutrophil transmigration ${ }^{7,9}$.

Phlebotonics are known as venoactive drugs, whose mechanism of action is not well established despite the availability of numerous studies concerning their pharmacological and clinical properties. Phlebotonics may have beneficial effects on oedema and on some signs and symptoms related to CVI such as trophic disorders, cramps, restless legs, swelling and paraesthesia when compared with placebo ${ }^{10}$. Aminaphtone $\left(\mathrm{C}_{18} \mathrm{H}_{15} \mathrm{NO}_{4}, \mathrm{AMNA}\right)$, a naphtohydrochinone used in the treatment of capillary disorders, has been reported to be effective in reducing vessel permeability and the healing of leg ulcers in patients with CVI and other pathological conditions ${ }^{11,12}$. In particular, in patients with idiopathic cyclic oedema syndrome, a clinical conditions that exhibits a vascular capillary hyperpermeability accompanied by oedema caused by the interstitial retention of fluid, a significant reduction in limb size was obtained after treatment with AMNA $(P<0.0001){ }^{12}$. AMNA acts on venous, capillary and lymphatic levels, reducing hyperpermeability, increasing venous resistance, and regulating lymphatic flux. This mechanisms of action result in reduced venous stasis, improved venous return, and, therefore, inducing tissues protection against toxins and free radicals, as demonstrated in a work of De Anna et al. in patients with chronic venous and lymphatic stasis ${ }^{11}$. Finally, the use of AMNA was associated with significant improvements in quality of life compared with placebo in CVI patients ${ }^{13}$. 


\begin{abstract}
Aim of the present study is to investigate the effect of AMNA on in vitro model of vascular endothelial permeability and to evaluate if the drug is able to stabilise capillary-like structures formed by HUVECs in an extracellular matrix model.
\end{abstract}

\title{
2. Materials and methods
}

\subsection{Aminaphtone}

AMNA was generously gifted by Baldacci Spa, Pisa, Italy. Lyophilised AMNA $0.1 \mathrm{~g}$ was diluted with dimethyl sulphoxide to obtain a $100 \mathrm{mg} / \mathrm{ml}$ concentration. The solution was then diluted with Medium 199 (Lonza, Basel, Switzerland) supplemented with $1 \%$ foetal bovine serum (FBS; Hyclone, South Logan, UT, USA), penicillin/streptomycin, HEPES (Lonza, Basel, Switzerland), glutamine (Sigma-Aldrich 3050 Spruce St., St. Louis, Missouri 63103 United States), heparin (Epsoclar) and bovine retina-derived extract as a complete growth medium.

\subsection{Cell isolation and culture}

HUVECs were isolated from fresh human umbilical cords by incubation with collagenase, (Invitrogen, Auckland, New Zealand) and cultured on gelatine-coated flasks in Medium 199 (Lonza) containing 20\% heat-inactivated FBS (Hyclone), sodium heparin (Epsoclar), penicillin/streptomycin (Lonza), HEPES (Lonza), glutamine (Sigma-Aldrich 3050 Spruce St., St. Louis, Missouri 63103 United States) and bovine retina-derived extract in humidified atmosphere $\left(37^{\circ} \mathrm{C}, 5 \% \mathrm{CO} 2\right)$. The P4-P5 cultures 
were cultivated until sub-confluence was reached. Thereafter, HUVECs were exposed to the different experimental conditions.

\subsection{Cell viability}

HUVECs, $3 \times 10^{4}$ cells/well, were seeded in 96-well plates in complete growth medium. After $72 \mathrm{~h}$, cells were washed with PBS and treated for $6 \mathrm{~h}$ with different concentrations of AMNA $(0-1-5-10-30-50-70-100 \mu \mathrm{g} / \mathrm{ml})$ in growth medium containing $1 \%$ FBS. After treatment, cells were washed twice with phosphate buffer saline (PBS) and viability was evaluated by WST-1 assay. WST-1 assay is a colorimetric assay based on the cleavage of tetrazolium salt (WST-1, 4-[3-(4-Iodophenyl)-2-(4-nitrophenyl)-2H-5tetrazolium]-1,3-benzene disulphonate, Roche Applied Science, Mannheim, Germany) by mitochondrial dehydrogenases in viable cells. Briefly, after treatment, HUVECs were incubated with tetrazolium salt $(10 \mu \mathrm{l} /$ well $)$ for $4 \mathrm{~h}$ at $37{ }^{\circ} \mathrm{C}, 5 \% \mathrm{CO}_{2}$. Then, the formazan dye formed was quantified by measuring the optical density at $450 \mathrm{~nm}$ (reference wavelength: $650 \mathrm{~nm}$ ), by a multiplate reader (Titertek). The absorbance directly correlated to the number of metabolically active cells. Viability was expressed as percent of viable cells, calculated from the ratio of absorbance after treatment to mean absorbance for the untreated control.

\subsection{Vascular permeability assay}

Vascular permeability was performed by Millipore assay kit (EMD Millipore Corporation Division Headquarters, Massachusetts, USA) according to the manufacture 
protocol. Briefly, $80 \%$ confluent HUVECs, were detached and plated on inserts $\left(3 \times 10^{4}\right.$ cells/insert) and incubated for $72 \mathrm{~h}$ at $37{ }^{\circ} \mathrm{C}, 5 \% \mathrm{CO}_{2}$, up to form a monolayer. Cells were then washed and treated with different concentrations of AMNA (0.5-1-5-10-20 $\mu \mathrm{g} / \mathrm{ml}$ ) for $6 \mathrm{~h}$ with or without $50 \mathrm{ng} / \mathrm{ml}$ VEGF (Recombinant Human VEGF 165 , Peprotech EC Ltd, London, UK) for $2 \mathrm{~h}$, in growth medium with 1\% FBS. At the end of incubation, all treatments were removed and an high molecular weight fluorescein isothiocyanate-dextran (FITC-dextran, MW 70KDa) was used to evaluate permeability. Plate was incubated in the dark for $20 \mathrm{~min}$ at room temperature. Permeation was arrested by removing the inserts from the wells. The levels of FITC-dextran was recorded by a sensitive fluorescence plate reader (Fluoroskan, Thermo Fisher $\left.{ }^{\circledR}\right)$, (Ex: $485 \mathrm{~nm}$; Em: 538). The amount of diffused dextran has determined using calibration curves established just with the stock solution.

\subsection{Western blot analysis of VE-cadherin}

To determine VE-cadherin and VE-cadherin phosphorylation expression, HUVECs were seeded in appropriated density in 6 multiwells and cultured in complete growth medium until confluence. Cells were afterwards washed and pre-treated with $10 \mu \mathrm{g} / \mathrm{ml}$ AMNA for $6 \mathrm{~h}$ and then with $50 \mathrm{ng} / \mathrm{ml}$ VEGF for $2 \mathrm{~h}$ in medium with $1 \% \mathrm{FBS}$. At the end of each treatment cells were lysed at $4^{\circ} \mathrm{C}$ for $1 \mathrm{~h}$ in lysis buffer $(50 \mathrm{mM}$ Tris- $\mathrm{HCl}$ pH 7.4, 150 mM NaCl, 1 mM PMSF, 1mM EDTA, 5 mg/ml Aprotinin, 5 mg/ml Leupeptin, 1\% Triton X-100, 1\% Sodium Deoxycholate, 0.1\% SDS) and centrifuged at $10,000 \mathrm{X} \mathrm{g}$ for $15 \mathrm{~min}$. The protein content of the supernatants was measured by 
Bradford method. Aliquots containing $50 \mathrm{mg}$ of cell lysate proteins were subjected to 7.5\% SDS-PAGE under reducing conditions and blotted onto nitrocellulose membrane filters. The blots were blocked for $2 \mathrm{~h}$ at $378 \mathrm{C}$ in $2 \%$ BSA, $1 \mathrm{mM} \mathrm{Na} 2 \mathrm{HPO} 4,1.7 \mathrm{mM}$ $\mathrm{NaH} 2 \mathrm{PO} 4,150 \mathrm{mM} \mathrm{NaCl}, 0.05$ Tween-20 (PBS-T). The nitrocellulose membranes were washed once with PBS-T for 15 min, three times for 5 min with $1 \mathrm{mM}$ PBS and immunoblotted for $2 \mathrm{~h}$ at room temperature with rabbit polyclonal anti-VE Cadherin (phospho Y685) antibody (Abcam Ltd) or with rabbit monoclonal anti-VE-cadherin antibody (Cell Signaling Technology, Boston, USA). After one washing with PBS-T and three washing with PBS, the blots were incubated for $1 \mathrm{~h}$ at room temperature with HRP labelled anti-rabbit IgG, washed with PBS, developed for 2 min with ECL reagent (Pierce) and exposed to Biomax film (Kodak Co.). The densitometry data of the protein bands were obtained using Image J software, and the objective protein expression was evaluated by the densitometry ratio of the objective proteins to $\beta$-actin.

\subsection{Immunofluorescent detection of VE-cadherin}

The distribution of VE-cadherin in HUVEC monolayers was assessed by immunofluorescent techniques using previously described procedure ${ }^{14}$ with modifications. Cells were placed on multiwell slides. Confluent cultures of HUVECs were pre-treated with AMNA $(10 \mu \mathrm{g} / \mathrm{ml})$ for $6 \mathrm{~h}$ and with VEGF $(50 \mathrm{ng} / \mathrm{ml})$ for $2 \mathrm{~h}$ in medium with $1 \%$ FBS. At the end of treatment, cells were washed three times with PBS containing $1 \mathrm{mM} \mathrm{CaCl}_{2}$ and $1 \mathrm{mM} \mathrm{MgCl}_{2}$ (DPBS) and then fixed with $4 \%$ formaldehyde at room temperature for $15 \mathrm{~min}$. The formaldehyde was then aspirated 
and the cells were washed three times with DPBS. The washed cells were then permeabilised with $0.5 \%$ Triton X-100 for $5 \mathrm{~min}$ at room temperature. Non-specific binding sites were blocked by incubation with 3\% BSA in DPBS for 5 min at room temperature. The BSA was then aspirated and the cells were immediately incubated with primary mouse monoclonal antibodies against human VE-cadherin $(10 \mathrm{mg} / \mathrm{ml}$ in DPBS) (Cell Signaling Technology, Boston, USA) for 1 to $12 \mathrm{~h}$ at $37^{\circ} \mathrm{C}$ in a humidified chamber. At the end of incubation the primary antibody were removed, cells were washed three times and incubated at $37^{\circ} \mathrm{C}$ for $30 \mathrm{~min}$ with FITC- conjugated anti-mouse secondary antibody (Cell Signaling Technology) diluted 1:200 and rhodaminephalloidin for F-actin staining (Cytoskeleton, Inc.) diluted 1:400 in DPBS. The chamber slides were then washed and mounted with Vectashield mounting medium containing DAPI (Vector Laboratories, UK). Slides were viewed under a fluorescence microscope (Nikon) equipped with a digital CCD camera and 20X objective. Images were recorded using AxioVision (Carl Zeiss MicroImaging, GmbH) software.

\subsection{In vitro capillary tube maintenance}

To evaluate the capability of AMNA to maintain capillary tubes formation, HUVECs were treated with $10 \mu \mathrm{g} / \mathrm{ml}$ AMNA for $6 \mathrm{~h}$ and then $7 \times 10^{4}$ cells/well were plated on Matrigel (BD Biosciences) for $48 \mathrm{~h}$. Matrigel was thawed on ice at $4{ }^{\circ} \mathrm{C}$ and used to coat 24-well plates for $30 \mathrm{~min}$ at $37^{\circ} \mathrm{C}$. Cells were monitored and optical microscopy images were captured at 2, 8, 24 and 48 h. Five independent images were taken for each well. 
To quantify angiogenic structures formed by HUVECs, computational morphometric analysis was performed ${ }^{10}$. Briefly, representative fields from each experimental setting were taken. Number of meshes (number of closed meshes) and master segment length (total length of the network) of capillary tubes, in five random fields for each sample and time of acquisition, were calculated using Angiogenesis Analyzer for ImageJ software ${ }^{13}$. Results for different experimental groups were expressed as mean \pm SD from three independent experiments. Representative pictures at higher magnification were also taken.

\subsection{Statistical analysis}

Data are presented as mean $\pm \mathrm{SD}$ of independent experiments. Comparisons were made using Student's t-test or by ANOVA when appropriate. Values of $\mathrm{P}<0.05$ were considered statistically significant. Statistical analysis was carried out using the GraphPad Prism 5 software (GraphPad Software, Inc., La Jolla, CA 92037 USA).

\section{Results}

\subsection{Effect of Aminaphtone on cell viability}

To determine non-toxic concentration of AMNA, HUVECs were incubated in the presence of different concentrations of drug (1-100 $\mu \mathrm{g} / \mathrm{ml})$. Dose-dependent HUVEC viability indicated that no significant cytotoxic effects were observed at AMNA 
concentrations below $30 \mu \mathrm{g} / \mathrm{ml}$. At concentration up to $30 \mu \mathrm{g} / \mathrm{ml}$ there was a rapid reduction in cell viability, Figure 1.

\subsection{Effect of Aminaphtone on endothelial cell permeability}

The effect of different concentrations of AMNA on VEGF-induced HUVEC

permeability has been shown in figure 2. VEGF-induced cell permeability was significantly reduced at a range concentration of $1-20 \mu \mathrm{g} / \mathrm{ml}$ AMNA $(\mathrm{P}<0.05$ vs VEGF), restoring normal condition. AMNA alone not affect cell permeability.

\subsection{VE-cadherin fluorescent detection}

To evaluate the effect of AMNA on VE-cadherin localisation, cells were fixed and processed for immunofluorescence (Figure 3) As showed in figure, VE-cadherin was localized as bright intense immunostaining at all cell-cell contacts (control and AMNA treatment). VEGF stimulation for $2 \mathrm{~h}$ reduced the staining of VE-cadherin at cell-cell contacts, that was now expressed in an irregular manner, and a loss of cell-cell adhesions. On the contrary, AMNA pre-treatment restored VE-cadherin staining at cellcell contacts that was distributed in a striped fashion, like controls.

\subsection{VE-cadherin expression}

To correlate the immunolocalization changes with protein expression, Western blot analysis of total VE-cadherin and phospho-VE-cadherin were performed (Figure 4).

Immunoblotting demonstrated that the levels of total VE-cadherin remained the same in 
all treatment conditions. However, phosphoY685-VE-cadherin resulted reduced by AMNA pre-treatment $(\mathrm{P}<0.005$ vs VEGF) and increased by VEGF treatment $(\mathrm{P}<0.001$ vs control), as confirmed by densitometry analysis. These data suggest a potential protective role of AMNA on VE-cadherin degradation induced by VEGF.

\subsection{In vitro capillary tube maintenance}

HUVECs, when seeded on Matrigel, formed capillary-like structures. This process has a rapid onset, beginning within $1 \mathrm{~h}$ and is completed by $8-12 \mathrm{~h}$; after this time the network starts to rearrange and completely disappears within $24-48 \mathrm{~h}$.

Figure 5 shows the effect of $10 \mu \mathrm{g} / \mathrm{ml}$ AMNA $6 \mathrm{~h}$ pre-treatment on capillary-like structure maintenance, formed by HUVECs. In figure 5 A, AMNA significantly reduced degradation of endothelial cells organised in endothelial cell cords on Matrigel at $24 \mathrm{~h}$ and $48 \mathrm{~h}$ compared with control. Figure 5 B, shows the number of meshes and master segment length of capillary tubes formed by HUVECs. After $48 \mathrm{~h}$, there was a significant difference in number of meshes and master segment length between control and AMNA-treated cells $(\mathrm{P}<0.01)$.

\section{Discussion}

CVI is characterised by venous hypertension associated with decrease in microcirculatory blood flow and increase in post-capillary permeability of the veins, leading to oedema of the legs and feet ${ }^{15}$. The most used phlebotropic drugs, or oedemaprotecting drugs, are the gamma-benzopyrone family (flavonoids) ${ }^{16}$. Results of clinical 
studies show that flavonoids decrease capillary permeability and increase capillary resistance, which could partly be explained by inhibition of leukocyte activation, migration, and adhesion ${ }^{16,17}$. As reported by Ramelet et al. (2000), this inhibition is linked to a significant decrease in plasma levels of endothelial adhesion molecules (VCAM-1 and ICAM-1) after flavonoids treatment ${ }^{18}$. Beside the clinical outcome in patients with CVI, AMNA has shown interesting endothelial-protective properties, inducing down-regulation of sELAM-1 and SVCAM-1 in patients with systemic sclerosis ${ }^{19}$. Moreover, AMNA is a molecule with a demonstrated anti-endothelin1 (ET1) effect in vitro, interfering with the transcription of the pre-pro-ET-1 (PPET-1) gene ${ }^{20}$. Furthermore, ET-1 is known to acts as a permeability factor in the vascular endothelium ${ }^{21-23}$. It is known that HUVECs treated with VEGF increased their ET-1 production in a concentration and time-dependent manner ${ }^{24}$. In addition, Chen et al. (2000), demonstrated that VEGF increased both ET-1 mRNA and ET-1 protein expression along with endothelial cell permeability in HUVECs cultured in normal glucose condition. Interestingly, they reported that ET-1 induces a disruption of the endothelial cell junctions ${ }^{25}$. Moreover, in a recent work, we demonstrated that AMNA reduced significantly ET-1 secretion in HUVECs ${ }^{26}$.

In this study, AMNA was able to restore vascular permeability induced by VEGF in a concentration range of 1-20 $\mu \mathrm{g} / \mathrm{ml}$. Inhibition of VE-cadherin function induces a reorganisation of the actin cytoskeleton leading to a loss of junctional VE-cadherin localization, reduces cell-cell adhesion and increases permeability ${ }^{27}$. It is know that VEGF stimulation reduces VE-cadherin staining at the adherent junction ${ }^{\text {7, 27-29. }}$. 
Moreover, it is generally accepted that the tyrosine phosphorylation of VE-cadherin is associated with weak junctions and impaired barrier function. In particular, it has been proved that VEGF enhance the permeability of HUVEC monolayers and increase tyrosine phosphorylation of VE-cadherin ${ }^{30}$. In our study, AMNA pre-treatment restored VE-cadherin localization at the cell-cell contacts. In addition, protein expression of total VE-cadherin remained the same in all treatment conditions, whereas phospho-tyrosin 685-VE-cadherin resulted increased by VEGF treatment (compared to control) and reduced by AMNA pre-treatment.

Finally, HUVECs, when seeded on Matrigel, formed capillary-like structures. This process has a rapid onset, beginning within $1 \mathrm{~h}$ and is completed by $8-12 \mathrm{~h}$; after this time the network starts to rearrange and completely disappears within $24-48 \mathrm{~h}$. We used Matrigel assay to evaluate the effect of AMNA pre-treatment on degradation time of capillary-like structures formed by HUVECs. In accordance with the role of VEcadherin in both formation and maintenance of capillary tubes in fibrin collagen gelover-gel assays ${ }^{7}$, our data showed that AMNA improved stability of endothelial cells organised in capillary-like structures, as observed after $48 \mathrm{~h}$.

\subsection{Limitations and future directions}

One potential limitation of this study was the completely absences of in vitro studies on the mechanism of action of AMNA and its intracellular pathway involved. Here, for the first time, the influence of AMNA on VE-cadherin modulation was suggested. Moreover, we lack of clinical experience of oedema reduction. 
Future direction may be an in vitro study on endothelial cells cultured from veins of patients with CVI to set up a personalized study. Finally, a multicentric clinical studies would be essential to confirm the effect of AMNA on oedema reduction mainly in leg ulcer.

\subsection{Conclusion}

AMNA is used to reduce lower limbs oedema in chronic venous insufficiency.

On the basis of our experience, we can suppose that the effect of AMNA is due to protection of VE-cadherin degradation induced by VEGF and to its effect on ET-1 expression. These properties of AMNA may also explain the stability of endothelial cells organised in extracellular matrix.

\section{Disclosures}

The authors declare no conflicts of interest. 


\section{References}

1. Nagy JA, Benjamin L, Zeng H, et al. Vascular permeability, vascular hyperpermeability and angiogenesis. Angiogenesis 2008; 11: 109-119.

2. Wu MH, Yuan SY and Granger HJ. The protein kinase MEK1/2 mediate vascular endothelial growth factor- and histamine-induced hyperpermeability in porcine coronary venules. J Physiol 2005; 563: 95-104.

3. Parsons JT, Horwitz AR and Schwartz MA. Cell adhesion: integrating cytoskeletal dynamics and cellular tension. Nat Rev Mol Cell Biol 2010; 11: 633-643.

4. Kelly M, Hwang JM and Kubes P. Modulating leukocyte recruitment in inflammation. J Allergy Clin Immunol 2007; 120: 3-10.

5. Dejana E and Del Maschio A. Molecular organization and functional regulation of cell to cell junctions in the endothelium. Thromb Haemost 1995; 74: 309-312.

6. Lampugnani MG and Dejana E. Interendothelial junctions: structure, signalling and functional roles. Curr Opin Cell Biol 1997; 9: 674-682.

7. Bach TL, Barsigian C, Chalupowicz DG, et al. VE-Cadherin mediates endothelial cell capillary tube formation in fibrin and collagen gels. Exp Cell Res 1998; 238: $324-334$.

8. Bach TL, Barsigian C, Yaen $\mathrm{CH}$, et al. Endothelial cell VE-cadherin functions as a receptor for the beta15-42 sequence of fibrin. J Biol Chem 1998; 273: 30719-30728. 9. Hordijk PL, Anthony E, Mul FP, et al. Vascular-endothelial-cadherin modulates endothelial monolayer permeability. J Cell Sci 1999; 112 ( Pt 12): 1915-1923. 
10. Martinez-Zapata MJ, Vernooij RW, Uriona Tuma SM, et al. Phlebotonics for venous insufficiency. Cochrane Database Syst Rev 2016; 4: CD003229.

11. De Anna D, Mari F, Intini S, et al. [Effects of therapy with aminaftone on chronic venous and lymphatic stasis]. Minerva Cardioangiol 1989; 37: 251-254.

12. Pereira de Godoy JM. Aminaphtone in idiopathic cyclic oedema syndrome. Phlebology 2008; 23: 118-119.

13. Belczak SQ, Sincos IR, Campos W, et al. Veno-active drugs for chronic venous disease: A randomized, double-blind, placebo-controlled parallel-design trial.

Phlebology 2014; 29: 454-460.

14. Chowdhury ZA, Barsigian C, Chalupowicz GD, et al. Colocalization of tissue transglutaminase and stress fibers in human vascular smooth muscle cells and human umbilical vein endothelial cells. Exp Cell Res 1997; 231: 38-49.

15. Nicolaides AN. Investigation of chronic venous insufficiency: A consensus statement (France, March 5-9, 1997). Circulation 2000; 102: E126-163.

16. Eberhardt RT and Raffetto JD. Chronic venous insufficiency. Circulation 2014; 130: 333-346.

17. Gulati OP. Pycnogenol(R) in chronic venous insufficiency and related venous disorders. Phytother Res 2014; 28: 348-362.

18. Ramelet AA. Pharmacologic aspects of a phlebotropic drug in CVI-associated edema. Angiology 2000; 51: 19-23. 
19. Scorza R, Santaniello A, Salazar G, et al. Effects of aminaftone $75 \mathrm{mg}$ TID on soluble adhesion molecules: a 12-week, randomized, open-label pilot study in patients with systemic sclerosis. Clin Ther 2008; 30: 924-929.

20. Scorza R, Santaniello A, Salazar G, et al. Aminaftone, a derivative of 4aminobenzoic acid, downregulates endothelin-1 production in ECV304 Cells: an in vitro Study. Drugs $R$ D 2008; 9: 251-257.

21. Levin ER. Endothelins. N Engl J Med 1995; 333: 356-363.

22. Vanhoutte PM. Endothelin-1. A matter of life and breath. Nature 1994; 368: 693-694.

23. Victorino GP, Newton CR and Curran B. Endothelin-1 decreases microvessel permeability after endothelial activation. J Trauma 2004; 56: 832-836.

24. Lee KJ, Kim MK, Park YH, et al. Vascular endothelial growth factor induces endothelin-1 production via matrix metalloproteinase-2 rather than endothelinconverting enzyme-1. Hypertens Pregnancy 2007; 26: 189-199.

25. Chen S, Apostolova MD, Cherian MG, et al. Interaction of endothelin-1 with vasoactive factors in mediating glucose-induced increased permeability in endothelial cells. Lab Invest 2000; 80: 1311-1321.

26. Frullini A, Da Pozzo E, Felice F, et al. Prevention of excessive endothelin-1 release in sclerotherapy: in vitro and in vivo studies. Dermatol Surg 2014; 40: 769-775. 27. Gumbiner BM. Regulation of cadherin-mediated adhesion in morphogenesis. Nat Rev Mol Cell Biol 2005; 6: 622-634. 
28. Gavard J and Gutkind JS. VEGF controls endothelial-cell permeability by promoting the beta-arrestin-dependent endocytosis of VE-cadherin. Nat Cell Biol 2006; 8: 1223-1234.

29. Yamaoka-Tojo M, Tojo T, Kim HW, et al. IQGAP1 mediates VE-cadherinbased cell-cell contacts and VEGF signaling at adherence junctions linked to angiogenesis. Arterioscler Thromb Vasc Biol 2006; 26: 1991-1997.

30. Esser S, Lampugnani MG, Corada M, et al. Vascular endothelial growth factor induces VE-cadherin tyrosine phosphorylation in endothelial cells. J Cell Sci 1998; 111 (Pt 13): 1853-1865. 
Figure 1. Dose-dependent effect of AMNA on cell viability. HUVECs were treated with different concentration of AMNA ( $1-5-10-30-50-70-100 \mu \mathrm{g} / \mathrm{ml}$ ) for $6 \mathrm{~h}$. Cell viability was evaluated by WST-1 colorimetric assay (Abs $450 \mathrm{~nm}$ ). Data are expressed as percentage of control of 3 independent experiments \pm SD.

\section{$53 \times 32 \mathrm{~mm}(600 \times 600$ DPI $)$}


Figure 2. Permeability of HUVEC monolayers to FITC-dextran. Cells were grown to confluency on Transwell filters and pre-treated with different concentrations of AMNA $(0.5-1-5-10-20 \mu \mathrm{g} / \mathrm{ml})$ for $6 \mathrm{~h}$ and than with or without VEGF $(50 \mathrm{ng} / \mathrm{ml})$ for $2 \mathrm{~h}$. Permeability was measured using FITC-dextran (MW $70 \mathrm{KDa})$ as described in Materials and Methods. Data are expressed as percentage of FITC-dextran diffusion of empty filter (no cells) and are representative of three independent experiments. Ex $485 \mathrm{~nm}$; Em $538 \mathrm{~nm}$. **P < 0.05 vs VEGF.

$86 \times 52 \mathrm{~mm}(600 \times 600 \mathrm{DPI})$ 

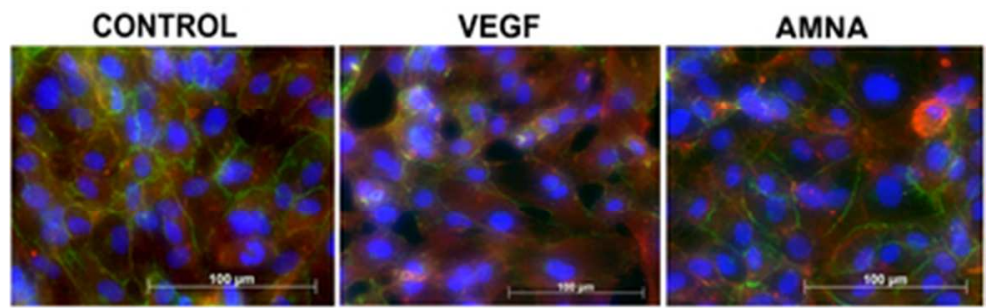

\section{AMNA + VEGF}

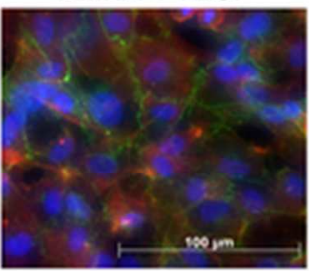

Figure 3. VE-cadherin localization in HUVECs. Confluent cell monolayers were pre-treated with AMNA (10 $\mu \mathrm{g} / \mathrm{ml}$ ) for $6 \mathrm{~h}$ and with VEGF ( $50 \mathrm{ng} / \mathrm{ml}$ ) for $2 \mathrm{~h}$. Cells were immunostained for VE-cadherin (green) and Factin (red). Cell nuclei were counterstained with DAPI (blue). All fluorescence images were taken at five different fields/well, and images are representative of three independent experiments (magnification 20X). 
Figure 4. VE-cadherin expression. HUVECs were cultured until confluences and pre-treated with $10 \mu \mathrm{g} / \mathrm{ml}$ AMNA for $6 \mathrm{~h}$ and then with $50 \mathrm{ng} / \mathrm{ml}$ VEGF for $2 \mathrm{~h}$ in medium with $1 \%$ FBS. Western blot analysis of cell lysate was performed. Anti-VE Cadherin (phospho-Y685) at $140 \mathrm{kDa}$ and anti-VE-cadherin antibody at 147 kDa were detected. Quantitative analysis has been normalized to beta-actin (as control). Samples derive from the same experiment and the gels and blots were processed in parallel. $* * P<0.005$ vs VEGF and $\S$ $\mathrm{P}<0.001$ vs control. 
(a) $2 h$ $8 h$
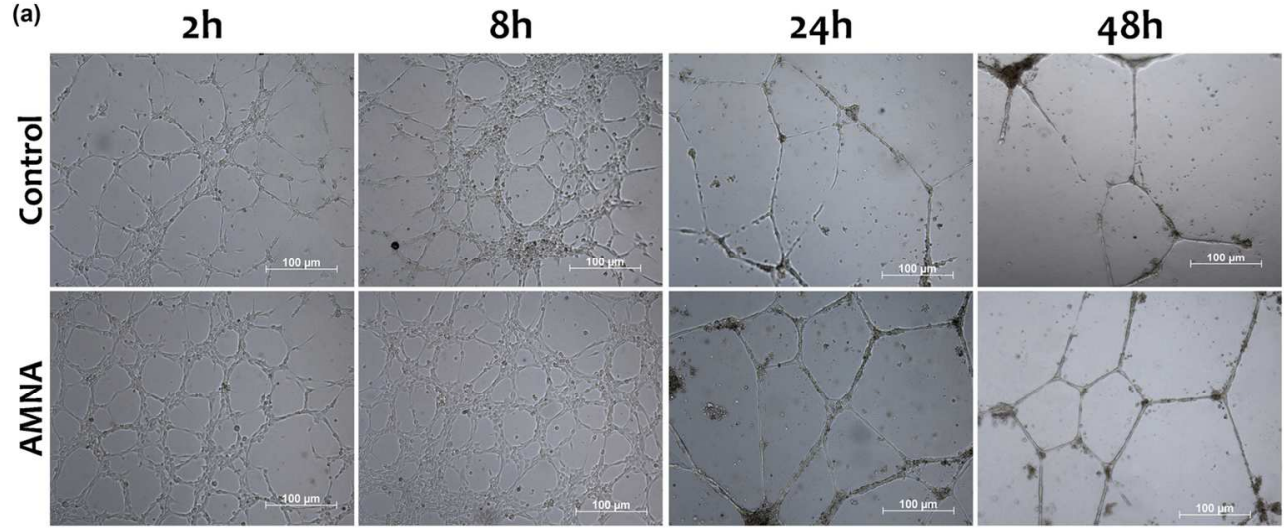

(b)
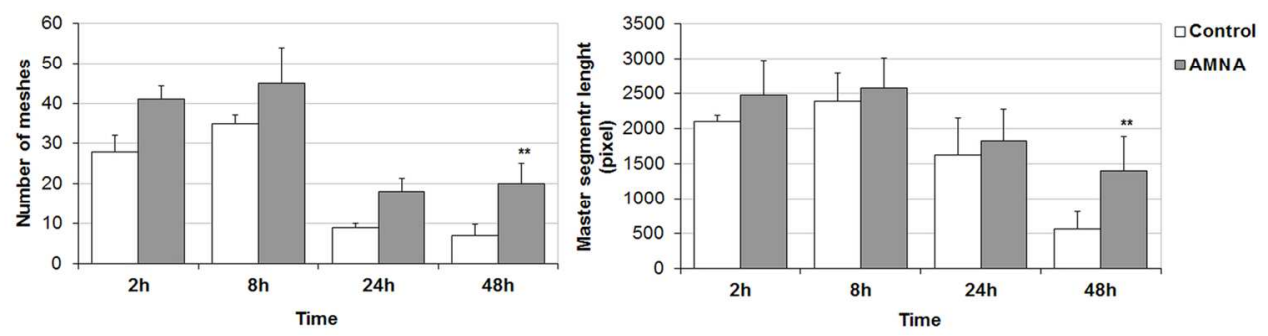

Figure 5. Capillary-like structures maintenance. Cells were treated for $6 \mathrm{~h}$ with $10 \mu \mathrm{g} / \mathrm{ml}$ AMNA and then $7 \times 104$ cells/well were plated on Matrigel for $48 \mathrm{~h}$. Images were acquired after 2-8-24-48 h. Images are representative of 5 random-field (original magnification $5 X)(A)$. Optical microscope images were analysed through Angiogenesis Analyzer for Image] software to measure number of meshes and master segment length of capillary tubes formed by HUVECs after 2-8-24-48 h (B). Five random fields for each sample and time of acquisition were analysed. Values in the graph are the mean from three independent experiments \pm $\mathrm{SD}$. $* * \mathrm{P}<0.01$ vs control. 


\section{Declarations}

Competing interests: The Authors declares that there is no conflict of interest

Funding: This research received no specific grant from any funding agency in the public, commercial, or not-for-profit sectors.

\section{Ethical approval: NA}

Guarantor: RD

Contributorship: FF and RD researched literature, wrote and conceived the study. EB was involved in protocol development, acquisition and analysis of data. TS and EI revised critically the manuscript for important intellectual content. AF and RD approved the version to be published. All authors reviewed and edited the manuscript and approved the final version of the manuscript.

\section{Acknowledgements: NA}

